\title{
THE IMPACT OF ORGANIZATIONAL CULTURE ON JOB SATISFACTION IN UNIVERSITIES OF PAKISTAN: A COMPETING VALUES FRAMEWORK PERSPECTIVE
}

\author{
Qaiser Rashid Janjua \\ Assistant Professor Air University School of Management, Islamabad \\ qaiser.janjua@mail.au.edu.pk \\ Aamer Hanif \\ Assistant Professor, Air University School of Management, Islamabad \\ ahanif@mail.au.edu.pk \\ Maliha Baig \\ Assistant Professor, Department of Management Studies, Bahria University, Islamabad \\ malihabaig.buic@bahria.edu,pk
}

\begin{abstract}
The main purpose of this research is to investigate the causal relationship between organizational culture types and job satisfaction of teaching faculty in universities. For organizational culture, Competing Values Framework is employed which includes four distinct cultures i.e. adhocracy, hierarchy, clan and market. Data were obtained from 169 full time faculty members from twelve universities of capital city, and analyzed through multiple linear regression in SPSS. The results show that overall employees are indifferent towards job satisfaction. Clan culture is found to be a strong predictor of job satisfaction whereas adhocracy, market and adhocracy cultures were detested. It is suggested that the universities in Pakistan should foster a collaborative and team culture where cohesion, camaraderie and internal harmony is important rather than following a typical structure of command, control, authority, innovation and competition. The management should cultivate teamwork, promote trust and openness; improve employee development through hands-on coaching, feedback, learning and development, and offer a compassionate environment in order to improve employee job satisfaction. This research also discusses demerits of clan culture and offers suggestions. Limitations of this study and future directions for research are also discussed.
\end{abstract}

Keywords: Organizational culture, Competing Values Framework, Job Satisfaction, Higher Education.

\section{INTRODUCTION}

Organizations all over the world are experiencing extraordinary changes. These changes not only accelerate the businesses to find out better operational solutions, but also help to survive and sustain within their markets through continuous growth and development. More importantly, the organizational culture appears to be an important factor for businesses to gain competitive advantage. Matsumoto and Juang (2016) denote culture as "the set of attitudes, values, beliefs, and behaviors shared by a group of people, may be unique for each individual and is transcended" (p.4).

Developing enabling and progressive organizational culture is among the primary management practices and is considered as a critical tool of strategic management. It helps to maintain the human performance by linking business practices with the overall goals and objectives of the organizations (Nitin, William \& Bruce, 2003). A significant body of literature highlights that organizational values, ethos, and character can intentionally or unintentionally influence the behavior of a large number of employees through different forms of learning. This seems to support that organizational culture influences psychological (affective), mental (cognitive) and behavioral components of organizational 
members (Cabassa, 2003; Ryder, Alden, \& Paulhus, 2000). According to a research conducted by HBR, the gains from output have increased a lot leaving behind the growth of employment. Organizations need to establish a quality culture where employees can consider quality as a personal value rather than just obeying the official orders. They should understand the need to promote a culture where employees can hear, talk and feel secure and comfortable within their environment (Ashwin \& Bryan, 2014). Also, organizations maintaining a quality culture results in employees making less errors besides enabling them to spend less time and money to recover from mistakes.

Organizations that operate globally can consider culture as a strong tool for managing the communication gaps and differences in employee's opinions (Erin, 2015). In a broader sense, building an employee-oriented organizational culture leads organizations to retain their internal customers i.e., employees that are not only able to create the desired value proposition but also are able to deliver it (Ahmed \& Rafiq, 2004; Al-Ali, Singh \& Al-Nahyan, 2017). The education sector of Pakistan is currently experiencing a profound growth. The number of public and private universities has expanded considerably. From 75 universities in 2005 to more than 250 universities in 2020 in Pakistan shows remarkable growth in this sector ${ }^{1}$. Also, the involvement of Higher Education Commission of Pakistan (HEC) towards the improvement of education standards is one of the factors behind such tremendous growth in the education sector. ${ }^{2}$ Most importantly, universities play a significant role in human resource development and individual, social and national perspectives. Here, culture acts as a catalyst and change medium whereas university professors and staff are the critical resources responsible for the quality of learning (Pawirosumarto, Setyadi \& Khumaedi, 2017). However, universities in Pakistan are facing challenges of substandard learning environment where organizational culture is likely to be one of the impeding factors (Grant Thornton, 2016). One of the popular opinions has been that it is the critical role of the type of organizational culture required in building a conducive environment for the employees within the universities (Cameron \& Quinn, 2011). Hisrich and Al-Dabbagh (2013) have been of the opinion that organizational culture diagnosis is of vital importance without which the strategic planning will yield limited results. Competing values framework helps not only to reveal the typology of organizational culture but also highlights the prevailing nature of culture that has a significant effect on employees' cognitive assessments and emotional state depicting satisfaction. There is an acute dearth of such research particularly in the context of higher education from the point-of-view of teaching faculty in Pakistan (Rukh \& Qadeer, 2018).

Therefore, this research is carried out with the objectives to determine relationships between organizational culture based on Competing Values Framework and job satisfaction of teaching faculty in universities. Specifically, the purpose is to explore the effect of four types of cultures i.e., Market, Adhocracy, Hierarchy and Clan on employee job satisfaction and also to determine the type of culture preferred by them. The study is useful for the university management to better understand their employee psyche and attitude towards their organization with respect to their job satisfaction. It will also enable them in developing a more progressive organizational culture that fosters quality learning environment, increased enrollment, and better organizational image amidst fierce competition from the public and the private sector universities.

\section{REVIEW OF LITERATURE}

Culture is considered as an environment made by people living together at same place. It consists of the norms and values, which helps to connect people (Gjuraj, 2013). According to Thrap (2009), culture is a combination of knowledge, attitude, beliefs, laws, values, morals and habits of individuals within a society. Culture has a diversity and it involves what the human beings think, do and make. It is a social pattern and can be transmitted from one generation to another through learned and shared behaviors. Organizational culture can be defined as the values, beliefs and hidden assumptions that organizational members have in common (Cameron \& Quinn, 2011; Denison, 1990; Deshpande \& Webster, 1989;

\footnotetext{
${ }^{1}$ https://www.unfpa.org/sites/default/files/resource-pdf/SWOP\%202014\%20fact\%20sheet\%20-\%20Youth\%20in\%20ASIA.pdf.

${ }^{2}$ https://www.thenews.com.pk/print/671857-hec
} 
The Impact of Organizational Culture on Job Satisfaction in Universities of Pakistan

Miron et al., 2004). It is collective in nature and is based on how incumbents think, feel and behave accordingly and is deeply entrenched in the organizations. It consists of habits and core values, which are visible and invisible respectively.

Schein (2010) posited that organizational culture is the set of beliefs and presumptions that a particular group discovers in order to deal with their internal as well as external challenges and depicts character of the organization. Culture has great impact on the overall performance of organizations. It helps to align the attitudes and behaviors of employees with the goals and objectives of organizations enhancing the level of job satisfaction among individuals that leads to better organizational performance (Cameron \& Quinn, 2011; Paais \& Pattiruhu, 2020).

Research on organizational culture shows that a strong or dominating culture within the organization focuses on the routine activities and common behavior among employees and decreases the organizational effectiveness in the changing environments, which leads to demoralization and lower levels of job satisfaction (Jennifer, 2014). Primarily, organizational culture consists of three main components including the attitude and behavior of individuals (the norm content), the overall shared beliefs of employees (culture consensus) and how strongly employees hold a particular culture (culture intensity) (Hodges, 2006). In order to stay competitive in the market, knowledge sharing is considered necessary for businesses. Some of the challenges faced by these businesses are manager's incompetency, wrong strategies and lack of understanding of the culture. Companies are sending their employees abroad for cross cultural trainings and foreign assignments to enhance job satisfaction and learn how to manage cross-cultural groups more effectively, while reducing the cultural shocks (Black, Gregersen \& Mendenhall, 1992). Organizations like universities need to create organizational culture as a positive environment that drives the competence and engagement of their faculty and staff (Asbari et al., 2020). Moreover, Caliskan \& Zhu (2020) reported significant association and impact of organizational culture features on factors of employee motivation towards student-centric learning and stressed on the use of innovative educational technologies.

Organizational culture can enhance the organizations effectiveness or act as a hurdle in the way of fulfilling organizations goals and objectives. In order to examine such issues, Competing Values Framework (CVF) is considered the most reliable and convenient model used in the field of organizational culture typology research. It measures the overall effectiveness of organizations (Cameron \& Quinn, 2011). The CVF when compared with the other models and instruments are the most reliable instruments for practical implications in the context of organizations (Yu, 2009). Some recent applications of the CVF are available in the case of public sector organizations (Zeb et al., 2021), community healthcare (O'Neill et al., 2021) green culture and environmental performance of firms (Maheshwari \& Kaur, 2021).

\section{Typology of Organizational Cultures (CVF)}

Researchers have differentiated the culture into many dimensions on the basis of their attributes and functionality. The most useful yardstick is Cameron and Quinn (2011) OCAI which is based on the Competing Values Framework (CVF). The CVF consists of two dimensions; first is related to the internal versus external focus of organizations and the second is based on the organizational preferences including stability and control verses flexibility and changes. These two dimensions form four quadrants that represent the major culture types (Cameron \& Quinn, 2011; Shurbagi \& Zahari, 2012). It is very helpful in explaining the cultural dimensions and types within organizations. The four cultural types being evolved from this model include hierarchy, market, clan, and adhocracy.

Hierarchical culture is preferred by the organizations whose purpose is to enhance productivity within their business operations. Such type of culture is highly characterized by strict rules and regulations for business practices. The top management has high power with less or sometimes low involvement of lower or middle management in decision making. The firms are less concerned about the needs and desires of individuals. A research was conducted by Lund (2003) on analyzing the effects of type of culture on job satisfaction in USA by using CVF. Results reveal that hierarchy culture is not preferred by employees and it has negative impact on job satisfaction (Cameron \& Quinn, 2011). Almost 
every organization considered hierarchical structure ideal until 1960s because it enabled very strong control and coordination within the organizations. The working environment is well organized by top management with clearly defined rules and regulations. A very formal communication with a bureaucracy is observed in hierarchical organizations that generally leads to slow decision making, less socialization among workers and lack of incompatibility in the outcomes that further leads to low level of employee oriented culture. So the organizations should use information technology in such type of cultures to make communication more effective (Widhiastuti, 2012; Alharbi \& Abederahim, 2018).

A market type culture was introduced to overcome new challenges faced by firms within their businesses. Researchers proposed that the market culture is the basis of strong effective management within organizations. The term market is used for outward orientation where organizations focus more on the external environment. They put more efforts in building strong relationships with outside customers, suppliers, contractors, government regulators and vendors. Lund (2003) analyzed that market culture is not preferred by employees and it has negative impact on job satisfaction. Further, the company's main goal is to increase their profit margins through clearly defined goals and targets keeping the customers at the center of their business practices. Their organizational values mostly consist of value creation, high productivity and competitive advantage (Cameron \& Quinn, 2011; O’Neill, De Vries, \& Comiskey, 2021).

The third type is the Clan culture that represents a family orientation based on common goals and values among individuals. Such type of culture reflects cohesion, employee involvement, and strong empathy. It enhances the positive relationship of cooperation and collaboration among individuals. The employees are considered as family members and are provided with strong support and guidance. All organizational practices revolve around 'internal customer' development and various employee engagement initiatives are also introduced to enhance their performance. The Japanese firms after World War II successfully implemented such culture within their organizations that led to remarkable success in their performance. Peter (2004) in his research found that organizational support is strongly preferred by employees. In a very recent study on Jordanian hotels, Tayeh and Mustafa (2021) found that the most prevalent cultures were clan and adhocracy where 'monitor and mentor' was found to be the main systemic theme whereas the employees needed increased flexibility, empowerment and recognition.

Adhocracy culture evolved when the business trend was shifting from industrialization to new information era. Such form of culture is preferred in the era of $21^{\text {st }}$ century when environment is highly uncertain and companies need to anticipate and respond quickly. In this modern era, the products and services lifecycle is decreasing and it is very difficult for organizations to stay competitive within the industry. The role of knowledge has increased and technology is changing rapidly, requiring organizations to develop a culture that fosters innovation (Zeb et al., 2021). The market leaders within the industries are mostly the first movers and they find new ways to satisfy their target markets. Hence, adhocracy culture has a positive effect on innovation orientation and enables managers to implement innovative strategies for their first mover advantage (Valencia, Jime, \& Valle, 2011).

\section{Organizational Culture and Job Satisfaction}

Many organizations all over the world are striving hard to establish wellbeing at their workplaces and it has also become focus of research. The organizational wellbeing is how employees perceive its quality and performance (Warr, 1992). The role of organizational culture in job satisfaction is studied frequently ranging from work arrangement to control and supervision (Spector, 1997). From the past few decades, researchers have shown great interest and attention in finding out relationship between organizational culture and job satisfaction (Yousef, 1998). The studies of organizational behavior have also proved that there exists a strong relationship between organizational culture and job satisfaction (Chen \& Francesco, 2000; Lok \& Crawford, 2001).

The basics of job motivation theory by Herzberg et al. (1959) consists of two important factors; motivators and hygiene. Accordingly, appreciation, responsibility, empowerment, need fulfillment and job opportunity creates high level of satisfaction among employees. These factors lead to selfactualization and creates positive attitude among employees towards their job. Whereas hygiene factors 
including pay, company's policies, working environment and job security which if not handled properly leads to dissatisfaction and poor performance of employees. Both, job satisfaction and dissatisfaction are two separate phenomena. Intrinsic factors are motivators that lead to high level of satisfaction whereas extrinsic factors are hygiene factors that lead to high level of dissatisfaction among employees. Another job characteristics model is given by Hackman and Oldman (1975), which shows the relationship between tasks and employees, attitude and behaviors towards those tasks. Meaningfulness of the tasks, responsibility to accept the results and knowledge of the actual outcome of the tasks significantly affect this relationship. For employees, job itself leads to high level of motivation. Task diversity, decision making authority, feedback, skills, variety and freedom are some of the ways to make tasks challenging and increases the intrinsic motivation of employees. Kennerly (1989) posited that there is a strong relationship between leadership styles, organizational culture and job satisfaction. The organizational culture that promotes respect, empathy, recognition and trust is responsible for higher level of satisfaction among employees. Billingsley and Cross (1992) identified factors responsible for higher level of commitment among teachers. They found that some work related factors such as organizational support, conflicts within different roles and stress levels are responsible for higher level of commitment and job satisfaction among teachers. Further, the nature of job, performance based salary and collaboration among employees are driven by the organizational cultures that culminates in employee satisfaction (Moody, 1996; Passos et al., 2012; Jabeen \& Isakovic, 2018). Figure 1 shows the discussed cultures and their salient characteristics.

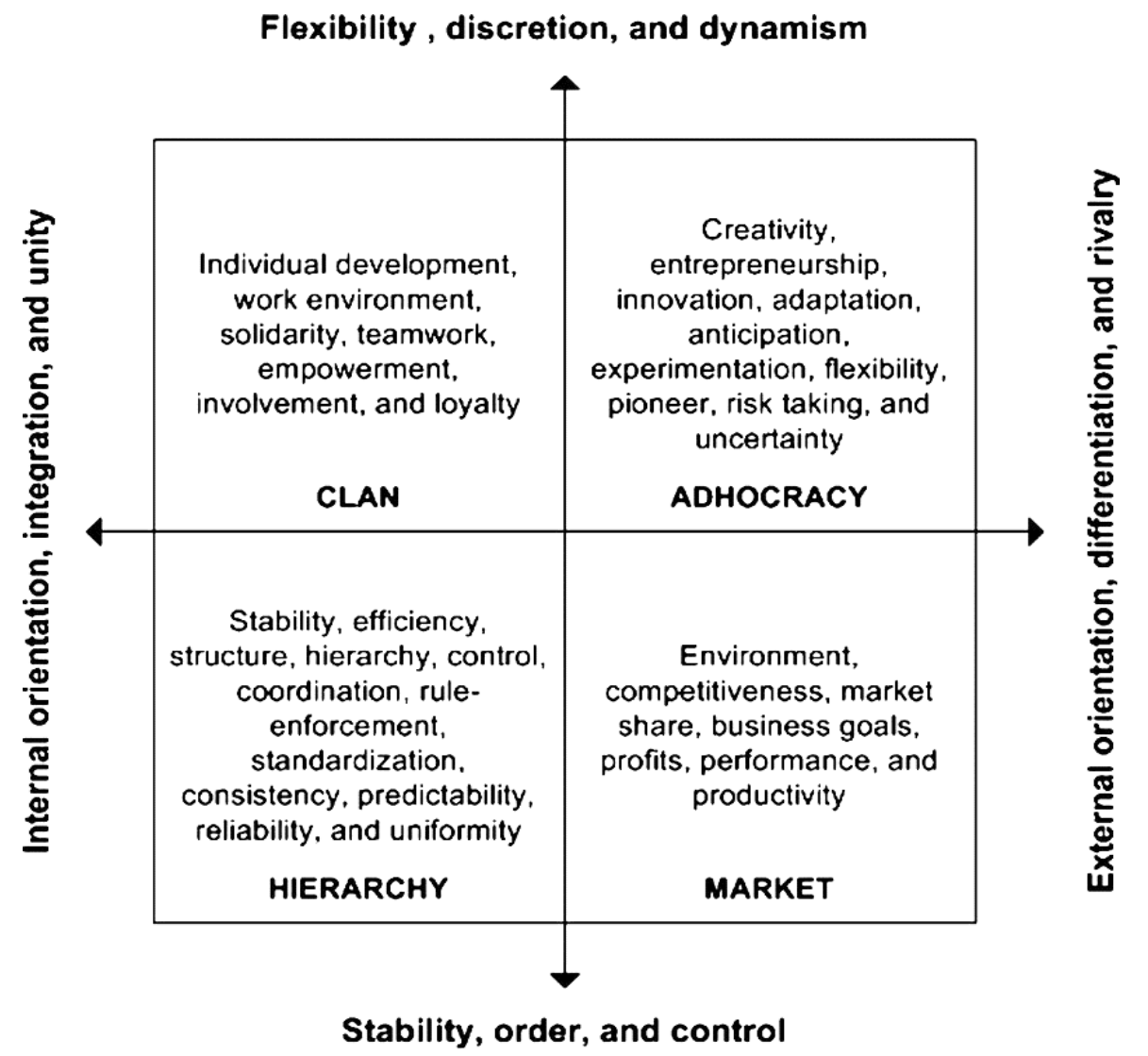

Figure 1: Organizational Culture Types (Cameron \& Freeman, 1991)

Many researchers used cognitive approach for job satisfaction and observed that how attitudes and behaviors of employees were determined. Spector (1997) observed that recognition, feedback, colleagues, fringe benefits, nature of tasks, safety, growth opportunities, company's values, culture and 
Janjua, Hanif \& Baig

career opportunities are some of the characteristics of job satisfaction. Goodman et al. (2001) found a significant relationship between organizational culture and work life balance. The results showed that there is a positive relationship between clan culture and high level of job satisfaction whereas hierarchical culture negatively affects the satisfaction level among employees. The study of Doughty et al. (2002) analyzed the perception of nurses towards their work environment and found that freedom of decision making, task orientation, co-workers bonding, innovation and senior management support were highly rated by nurses. Lund (2003) studied the four culture types and their impact on job satisfaction using CVF model. The study showed that the cultural attributes including teamwork, flexibility and cohesiveness leading to high clan culture and attributes including innovation, creativity and adoptability leading to high level of adhocracy culture showed a positive impact on job satisfaction. The market and hierarchical culture, on the other hand showed negative association with the job satisfaction among workers. Peter's (2004) study revealed that there is a strong relationship between employee empowerment, job satisfaction and organizational commitment. The organizational support and innovation have positive impact on job satisfaction whereas bureaucratic culture negatively affects job satisfaction among employees. Silverthorne (2004) studied the relationship between organizational culture, job satisfaction and organizational commitment. The author used a typology of three organizational culture types, namely supportive, innovative and bureaucratic. The results indicated that a bureaucratic culture resulted in the lowest levels of job satisfaction and commitment, while a supportive culture resulted in the highest levels of job satisfaction and commitment followed by an innovative culture as the next highest.

Generally, job satisfaction has many dimensions and is influenced by internal and external factors including individual's values, ethics, personality traits, job nature and job opportunities etc. (Davies et al., 2006). Job satisfaction is one of the dimensions of organizational wellbeing which consists of the attributes including social networking, physical and mental health, happiness, incentives and team building among employees (Grant et al., 2007). Chang and Lee (2007) found a strong connection between leadership style, organizational culture and job satisfaction among employees working in banks. They found that leadership style and organizational culture has a strong and positive effect on the overall operations of the organizations that leads to high level of job satisfaction. San (2009) found that job satisfaction has significant role between organizational culture and turnover intentions. The consensual culture appears to be the healthiest and preferred culture among employees and has a very strong impact on the level of job satisfaction. Jo et al. (1999) studied the relationship between organizational culture types and overall performance of firms in Korea and found a strong relationship between culture and employee job satisfaction. Further, they found that human oriented culture has positive effect whereas hierarchical culture has less or negative effect on job satisfaction.

Research in organizational behavior domain shows that there is a strong relationship between organizational culture and job satisfaction among individuals and it is important to ascertain the typology of prevalent culture from the incumbents' perspective (Chen \& Francesco, 2000; San et al., 2009; Macintosh \& Doherty, 2010; Shurbagi \& Zahari, 2012). Some research on CVF and job satisfaction in the local context revealed that hierarchy and market cultures are positively associated with trust and job satisfaction among employees (Gull \& Azam, 2012). However, the research remains elusive as to what type of culture is perceived positively by faculty working in universities (Nukic \& Huemann, 2016) especially in Pakistan.

Based on the literature review above, we can hypothesize that:

$\mathrm{H}_{1}$ : Adhocracy culture affects job satisfaction of teaching faculty in universities

$\mathrm{H}_{2}$ : Market culture affects job satisfaction of teaching faculty in universities

$\mathrm{H}_{3}$ : Hierarchy culture affects job satisfaction of teaching faculty in universities

$\mathrm{H}_{4}$ : Clan culture affects job satisfaction of teaching faculty in universities.

\section{THEORETICAL FRAMEWORK}

On the basis of literature review, the following variables related to organizational culture types are gathered. The impact of independent variables of four cultural types including clan, adhocracy, hierarchy 
and market on dependent variable including job satisfaction along with the role of organizational culture as an intervening variable is illustrated in Fig 2.

$$
\mathrm{JS}=\alpha+\beta_{1} \mathrm{Cl}+\beta_{2} \mathrm{Adh}+\beta_{3} \text { Hier }+\beta_{4} \text { Mrkt }
$$

Where:

JS = Job Satisfaction

$\mathrm{Cl}=$ Clan Culture

Adh. $=$ Adhocracy Culture

Hier. = Hierarchy Culture

Mrkt. $=$ Market Culture

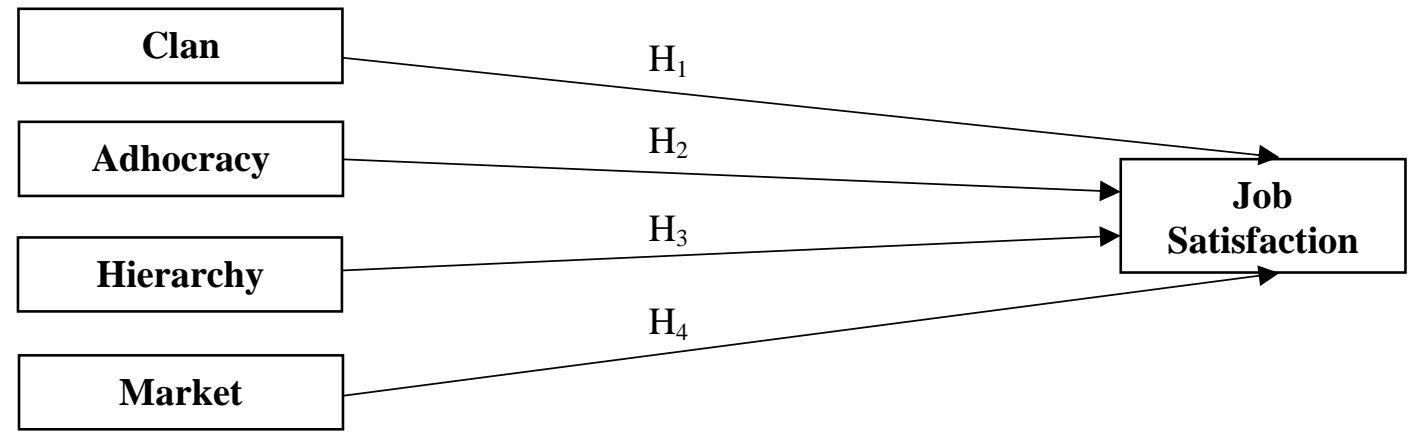

Figure 2: Theoretical Model

\section{METHODOLOGY}

This study has adopted the Organizational Culture Assessment Instrument (OCAI) developed by Cameron \& Quinn (2011), which is based on Competing Values Framework developed by Quinn \& McGrath (1985). Employee satisfaction scale has been adopted from Sahi et al. (2017). The instrument is a five point Likert-type scale, anchoring from "strongly disagree" (1) to "strongly agree" (5). OCAI comprises of six organizational cultural elements that relates to the four organizational cultures. Respondents are to divide 100 points depending on the similarity of the organizational culture to that of their organization.

The population of this study included fulltime teaching faculty members in public and private sector universities under general category in the city of Islamabad. Data were gathered from the faculty of twelve public sector universities. With a total population of 445 full time faculty members, a sample of 180 faculty members was estimated at $90 \%$ confidence level and $10 \%$ margin of error. The total sample size achieved was 169 . The sampling technique employed essentially is a convenience sampling procedure. Respondents were approached primarily through email and paper survey using an online google docs link and their responses were recorded accordingly.

\section{Data Analysis and Interpretation}

Table 1 shows the mean of the four items for satisfaction. The mean is 2.941 indicating indifferent employee satisfactions towards their job in the university.

\section{Table 1}

Descriptive Statistics

\begin{tabular}{ccccc}
\hline Job Satisfaction & Mean & Minimum & Maximum & N of Items \\
\hline Item Means & 2.941 & 2.763 & 3.238 & 4 \\
\hline
\end{tabular}


Table 2

Reliability (Job Satisfaction)

\begin{tabular}{cc}
\hline Cronbach's Alpha & N of Items \\
\hline .828 & 4 \\
\hline
\end{tabular}

Table 2 shows the Cronbach's alpha reliability coefficient for job satisfaction. The closer Cronbach's alpha coefficient is to 1.0 the greater the internal consistency of the items in the scale. The test is considered imperative for Likert type scales. The value of Cronbach's Alpha is 0.828 indicating reasonable inter-item correlations among the individual items in the dimensions or a reasonable variance commonality among the items in the instrument. Reliability coefficients for organizational culture types cannot be calculated owing to the nature of the instrument.

Table 3

Descriptive Statistics

\begin{tabular}{ccccc}
\hline & Clan & Adhocracy & Hierarchy & Market \\
\hline Mean & 24.89 & 18.96 & 33.15 & 22.85 \\
Minimum & 4.17 & 4.17 & 13.35 & 5.00 \\
Maximum & 50.00 & 41.66 & 73.34 & 55.00 \\
\hline
\end{tabular}

The foremost finding of the OCAI survey indicate the Hierarchy culture as the prevailing culture in public sector universities. This indicates a more authoritative disposition of management. The second most prevalent culture is the clan closely followed by market culture. Finally, the least prevalent culture is that of adhocracy (See Table 3).

Table 4 Correlations

\begin{tabular}{cccccc}
\hline & Hierarchy & Clan & Market & Adhocracy & Job Sat \\
\hline Hierarchy & 1 & $-.564^{* *}$ & $-.422^{* *}$ & $-.679^{* *}$ & $-.304^{* *}$ \\
Clan & $-.564^{* *}$ & 1 & $-.366^{* *}$ & .180 & $.427^{* *}$ \\
Market & $-.422^{* *}$ & $-.366^{* *}$ & 1 & .107 & $-.184^{*}$ \\
Adhocracy & $-.679^{* *}$ & .180 & .107 & 1 & $-.218^{*}$ \\
Job Sat & $-.304^{* *}$ & $.427^{* *}$ & $-.184^{*}$ & $-.218^{*}$ & 1 \\
\hline
\end{tabular}

**. Correlation is significant at the 0.01 level (2-tailed).

The bivariate Pearson correlation matrix obtained for the interval-scaled variables as shown in Table 4 indicates that Hierarchy $(r=-.304, p<.001)$ has negative correlation with satisfaction followed by a negative and significant correlation with Market culture $(-.184, p<.005)$. On the other hand, Clan culture has a significant positive correlation with job satisfaction $(r=.427, p<.001)$ and Adhocracy culture is negatively associated with job satisfaction and is significant $(r=-.218, p<.005)$. The predictors show mixed correlations among themselves. For instance, the relationship between hierarchy culture and all other cultures is negatively correlated and highly significant indicating opposing/distinct perceptions of employees. Similarly, clan culture is negatively associated with Hierarchy and Market cultures. Since none of the correlation values are more than 0.80 , the chances of multi-collinearity is apparently not an issue.

Table 5

Model Summary

\begin{tabular}{lllclll}
\hline Model & R & R Square & $\begin{array}{c}\text { Adjusted R } \\
\text { Square }\end{array}$ & $\begin{array}{c}\text { Std. Error of } \\
\text { the Estimate }\end{array}$ & F & Sig \\
\hline
\end{tabular}


Table 5 shows the adjusted R-Square value of 0.410; as a predictor of the trend, the value shows that the model explanatory power is 41 percent and the remaining 59 percent is unexplained. The theoretical model has reasonable explanatory power and can further be expanded by including more variables and/or increasing the sample size by including more staff. The $\mathrm{F}$ statistic is significant $(\mathrm{F}=20.51$, $p<.001$ ) showing a goodness of fit of the model as the null hypothesis of all betas i.e $\beta_{\mathrm{j}}=0, j=1,2, \ldots \mathrm{p}$. is rejected.

Table 6

Coefficients

\begin{tabular}{ccccccccc}
\hline & & \multicolumn{2}{c}{$\begin{array}{c}\text { Unstandardized } \\
\text { Coefficients }\end{array}$} & \multicolumn{2}{c}{$\begin{array}{c}\text { Standardized } \\
\text { Coefficients }\end{array}$} & \multicolumn{3}{c}{$\begin{array}{c}\text { Collinearity } \\
\text { Statistics }\end{array}$} \\
\cline { 3 - 8 } Model & $\mathrm{B}$ & Std. Error & Beta & $\mathrm{t}$ & Sig. & Tolerance & VIF \\
\hline & (Constant) & 2.522 & .409 & - & 6.163 & .000 & - & - \\
& Clan & .0310 & .009 & .376 & 3.445 & .023 & .818 & 1.223 \\
& Market & -.0223 & .010 & -.236 & -2.232 & .034 & .835 & 1.197 \\
& Adhocracy & .0210 & .008 & -.211 & -2.625 & .046 & .933 & 1.072 \\
& Hierarchy & -.0191 & .007 & -.195 & -2.728 & .038 & .725 & 1.379 \\
\hline
\end{tabular}

a. Dependent Variable: Job Satisfaction

Table 6 shows the beta coefficients of all the cultures (predictors) relative to job satisfaction (dependent). Specifically, Job satisfaction of employees is found to be strongly and positively dependent on Clan culture $(\beta=.376, p<.05)$. On the other hand, market, adhocracy and hierarchy cultures are found to be statistically significant but with negative beta coefficients indicating negative influence on job satisfaction $(\beta=-.236, p<.005 ; \beta=-.211, \mathrm{p}<.005 ; \beta=-.195, \mathrm{p}<.005)$. Consequently, $\mathrm{H}_{1}$ to $\mathrm{H}_{4}$ are supported. The collinearity statistic for each variable shows VIF values less than the threshold value of 4 and tolerance values greater than 0.25 ruling out any multicollinearity issues among the predictors.

\section{DISCUSSION}

The aim of this research was to explore the impact of four different types of cultures on employee job satisfaction in the university sector. The study employed popular organizational culture assessment technique based on competing values framework. It is found that employees i.e., the teaching faculty of the universities, prefer clan culture and resent the prevailing market, hierarchical and adhocracy cultures. Importantly, clan culture is the most powerful type of culture in universities in influencing job satisfaction levels. Clan has its roots in the structure of the Japanese business management practices which fosters problem solving through mutual collaboration and operates more like a family culture where individuals value cohesion, a caring working environment, group commitment, and loyalty with each other (Tuan, 2012). Clan cultures value teamwork and focus on quality of interpersonal relationships in terms of trust and openness (Lee et al., 2016). It develops employees through coaching, feedback and learning, and involves looking after each other in compassionate and emphatic ways (Peter, 2004; Jabeen \& Isakovic, 2018). The leadership is hands-on and intimate where members are led by example. The outcomes of such culture is better work-life quality, less stress, improved sense of belongingness, more productivity, better job satisfaction and lesser attrition (Chidambaranathan \& Regha, 2016). Nevertheless, protagonist of clan culture in organizations advise that the management, in cultivating compassionate relationships should pronounce clear boundaries to harness platonic interactions and avoid non-preferred and out-of-scope work activities. Congeniality, an inherent ingredient of clan culture, may lead to flawed group decision 
Janjua, Hanif \& Baig

making and judgment bias for the sake of harmony. Finally, clan is essentially an internally driven culture and may compromise organizational maneuverability to assess and respond to external market changes (Reader, Gillespie, Hald \& Patterson, 2020).

\section{CONCLUSION AND IMPLICATIONS}

Implementation of an effective culture within an organization depends upon various competencies and managerial skills that have been recognized in past studies. These skills and competencies are well categorized in CVF model. Skills required by managers for implementing a clan culture consist of managing high performance teams, nurturing interpersonal relationships, and creating and implementing self-development of other individuals. The higher management of universities in Pakistan should focus less on strict rules, structure and control and more on the flexibility in their policy and practices. It is evident that employees want to be driven through vision, shared goals, and common outcomes. Instead of a hierarchically encrusted culture prevailing in the universities, the organizational culture should be more flexible, empowering and emphatic.

It is also important to note that the effects of any university culture trickles down to the students who are a major stakeholders and are the main partners in the co-creation of value. This essentially means that when university employees and faculty feel being in a team and being cared and taken-care of, the same embodied values are transcended to the students through regular instructor-student interactions. This will surely bring about better performance of not only the instructors in the class but also among the students who are supposed to learn and work in teams. This collaborative environment goes beyond the student-instructor relationship i.e., the alumni and the industry at large with whom better and more fruitful interactions are likely to be developed. Overall, such change is surely to bring about better name and acclaim, increased faculty and staff satisfaction, student retention and repurchases intentions, more enrollments that would result in improved financial well- being of the universities.

\section{REFERENCES}

Ahmed, P. K., \& Rafiq, M. (2004). Internal marketing: Tools and concepts for customer focused management. Butterworth-Heinemann: Oxford.

Al-Ali, A. A., Singh, S. K., Al-Nahyan, M., \& Sohal, A. S. (2017). Change management through leadership: the mediating role of organizational culture. International Journal of Organizational Analysis, 25(4), 723-739.

Alharbi, S. H., \& Abedelrahim, S. (2018). Organizational culture assessment using the competing values framework (CVF) in public universities in Saudi Arabia: A case study of Tabuk University. The International Journal of Business and Management, 6(2), 2018.

Asbari, M., Purwanto, A., Ong, F., Mustikasiwi, A., Maesaroh, S., Mustofa, M., \& Andriyani, Y. (2020). Impact of hard skills, soft skills and organizational culture: Lecturer innovation competencies as mediating. Journal of Education, Psychology and Counseling, 2(1), 101-121.

Black, J. S., Gregersen, H.B., \& Mendenhall, M. (1992). Global assignments: Successfully expatriating and repatriating international managers. San Francisco, CA: Josey-Bass.

Cabassa, L. J (2003). Measuring acculturation: Where we are and where we need to go. Hispanic Journal of Behavioral Sciences, 25(2),127-146.

Cameron, K. S. \& Freeman, S. (1991). Cultural congruence, strength, and type: Relationships to effectiveness. Research in organizational change and development, 5, 23-58.

Cameron, K. S., \& Quinn, R. E. (2011). Diagnosing and changing organizational culture: Based on the competing values framework ( $3^{\text {rd }}$ ed.). San Francisco, CA: Jossey-Bass.

Caliskan, A., \& Zhu, C. (2020). Organizational Culture and Educational Innovations in Turkish Higher Education: Perceptions and Reactions of Students. Educational Sciences: Theory and Practice, 20(1), 20-39.

Chen, Z. X., \& Francesco, A. M. (2000). Employee demography, organizational commitment, and turnover intentions in China: Do cultural differences matter? Human Relations, 53(6), 869-887. 
Chidambaranathan, K. \& Regha, V. S. (2016). Diagnosing the organizational culture of higher education libraries in the United Arab Emirates using the Competing Values Framework. Library and Information Science Research Electronic Journal, 26(2), 99-112.

Deal, T., \& Kennedy, A. (2000). The new corporate cultures: Revitalizing the workplace after downsizing, mergers, and reengineering. Reading, MA: Perseus Books.

Denison, D. (1990). Corporate culture and organizational effectiveness, Wiley, New York.

Deshpande, R. \& Webster, F. (1989). Organizational culture and marketing: Defining the research agenda. Journal of Marketing, 53(1), 3-15.

Gjuraj, E. (2013). The importance of national culture studies in the organizational context. European Scientific Journal, 9(11), 160-180.

Goodman, E., Zammuto, R., \& Gifford, B. (2001). The competing values framework: Understanding the impact of organizational culture on the quality of work life. Organization Development Journal, 19(3), 58-68.

Grant, A.M., Christianson, M.K., \& Price, R.H. (2007). Happiness, health, or relationships? Managerial practices and employee well-being tradeoffs. Academy of management perspectives, 21, 51-63.

Grant Thornton (2016). Public Expenditure Tracking Survey (PETS). Final Report, submitted to Higher Education Commission of Pakistan.

Gull, S. \& Azam, F. (2012). Impact of organizational culture type on job satisfaction level of employees' in different organizations of Lahore, Pakistan. International Journal of Academic Research in Business and Social Sciences, 2(12), 2222-6990.

Hodges, C. (2006). "PRP culture" A framework for exploring public relations practitioners as cultural intermediaries. Journal of Communication Management, 10(1), 80-93.

Jabeen, F., \& Isakovic, A. A. (2018). Examining the impact of organizational culture on trust and career satisfaction in the UAE public sector: A competing values perspective. Employee Relations, 40(6), 1036-1053.

Jennifer, A. \& Chatman, D. F. (2014). Parsing organizational culture: How the norm for adaptability influences the relationship between culture consensus and financial performance in high technology firms. Journal of Human behavior, 35(6), 785-808.

Jo, H. S., Lee, S., Cho, W., Chun, K. \& Moon, O. (1999), The relationship of organizational culture and organizational effectiveness at the general hospital. Korean Journal of Preventive Medicine, 32(3), 374-82.

Lee, J. C., Shiue, Y.C. \& Chen, C.Y. (2016). Examining the impacts of organizational culture and top management support of knowledge sharing on the success of software process improvement. Computers in Human Behavior, 54, 462-474.

Lok, P \& Crawford, J. (2004). The effect of organizational culture and leadership style on job satisfaction and organizational commitment: A cross-national comparison. Journal of Management, 23(4), 321-338.

Lund, D. (2003). Organizational culture and job satisfaction. Journal of Business \& Industrial Marketing, 18(3), 219-36.

Macintosh, E., \& Doherty, A. (2010). The influence of organizational culture on job satisfaction and intention to leave. Sport Management Review, 13(2), 106-17.

Matsumoto, D. R., \& Juang, L. P. (2008). Culture and psychology. Belmont, CA: Wadsworth/Thomson.

Maheshwari, S., \& Kaur, A. (2021). Green HRM System and Green Culture: A Conceptual Model Towards Green Competing Values Framework. In Academy of Management Proceedings 2021(1), 11560. Briarcliff Manor, NY 10510: Academy of Management.

Meyer, E. (2015). When culture doesn't translate. Harvard Business Review.

Nohria, N., Joyce, W.\& Roberson, B. (2003). What really works. Haward Business Review.

Nukic, I. S., \& Huemann, M. (2016). Organizational culture of the Croatian construction industry, Engineering, Construction and Architectural Management, 23(2), 237-260. 
Reader, T. W., Gillespie, A., Hald, J. \& Patterson, M. (2020). Unobtrusive indicators of culture for organizations: a systematic review. European Journal of Work and Organizational Psychology, 29(5), 633-649.

O’Neill, D., De Vries, J., \& Comiskey, C. M. (2021). Leadership and community healthcare reform: a study using the Competing Values Framework (CVF). Leadership in Health Services, (ahead-ofprint).

O'Reilly, C. A., Caldwell, D. F., Chatman, J. A., \& Doerr, B. (2014). The promise and problems of organizational culture: CEO personality, culture, and firm Performance. Group \& Organization Management, 39(6), 595-625.

Paais, M., \& Pathiruho, J. R. (2020). Effect of motivation, leadership, and organizational culture on satisfaction and employee performance. The Journal of Asian Finance, Economics, and Business, 7(8), 577-588.

Passos, O. M., Dias-Neto, A. C., \& da Silva-Barreto, R. (2012). Assessing the relevance of organizational culture in software process improvement initiatives, CIBSE, 70-83.

Pawirosumarto, S., Setyadi, A., \& Khumaedi, E. (2017). The influence of organizational culture on the performance of employees at University of Mercu Buana. International Journal of Law and Management, 59(6), 950-963.

Peters, T., \& Waterman, R. (2004). In search of excellence: Lessons from America's best-run companies $\left(2^{\text {nd }}\right.$ ed.). London: Profile Books.

Ryder, A. G., Alden, L. E., \& Paulhus, D. L. (2000). Is acculturation unidimensional or dimensional? A head-to-head comparison in the prediction of personality, self-identity, and adjustment. Journal of Personality and Social Psychology, 79, 49-65.

Sahi, S. K. (2017). Psychological biases of individual investors and financial satisfaction. Journal of Consumer Behavior. 16, 511- 535.

Schein, E. H. (2010). Organizational Culture and Leadership. Hoboken, NJ: John Wiley \& Sons, Inc.

Shurbagi, A \& Zahari, I. (2012). The Relationship between Organizational Culture and Job Satisfaction in National Oil Corporation of Libya. International Journal of Humanities and Applied Sciences, 1(3), 227-438.

Silverthorne, C. (2004). The impact of organizational culture and person-organization fit on organizational commitment and job satisfaction in Taiwan. Leadership \& Organization Development Journal, 25(7), 592-99.

Smart, J. C., \& Hamm, R. E. (1993). Organizational effectiveness and mission orientations of two-year colleges. Research in Higher Education, 34(4), 489-502.

Srinivasan, A., \& Kurey, B. (2014). Creating a Culture of Quality. Harvard Business Review.

Tayeh, S. N. A., \& Mustafa, M. H. (2021). Applying competing values framework to Jordanian hotels, Anatolia, DOI: 10.1080/13032917.2021.1938154.

Tharp, B.M. (2009). Defining “culture” and "organizational culture:” From anthropology to the office. Haworth.

Tuan, L.T. (2012). What trust grows through upward influence?, Asia-Pacific Journal of Business Administration, 4(2), 158-181.

Valencia, J.C.N., Jime, D.J. \& Valle, R.S. (2011). Innovation or imitation? The role of organizational culture. Management Decision, 49(1), 55 - 72.

Warr, P.B. (1992). Age and occupational well-being. Psychology and Ageing, 7(1), 37-45.

Yousef, D. A. (1998). Correlates of perceived leadership style in a culturally mixed environment. Leadership and Organization Development Journal, 19(5), 275-284.

$\mathrm{Yu}, \mathrm{T}$. (2009). A review of study on the competing values framework. International journal of business and management, 4(7), 37-42.

Zeb, A., Akbar, F., Hussain, K., Safi, A., Rabnawaz, M., \& Zeb, F. (2021). The competing values framework model of organizational culture, innovation and performance. Business Process Management Journal, 27(2), 658-683. 